\title{
Revising a gastric conduit after esophagectomy: How do we get it right?
}

\author{
Lara W. Schaheen, MD, Kyla D. Joubert, MD, and James D. Luketich, MD
}

\author{
From the Department of Cardiothoracic Surgery, University of Pittsburgh, Pittsburgh, Pa. \\ Disclosures: Authors have nothing to disclose with regard to commercial support. \\ Received for publication May 26, 2017; accepted for publication May 31, 2017; available ahead of print Aug 4, \\ 2017. \\ Address for reprints: Lara W. Schaheen, MD, Department of Cardiothoracic Surgery, University of Pittsburgh, \\ Pittsburgh, PA 15213 (E-mail: schaheenlw@upmc.edu). \\ J Thorac Cardiovasc Surg 2017;154:1461-2 \\ $0022-5223 / \$ 36.00$ \\ Copyright (C) 2017 by The American Association for Thoracic Surgery \\ http://dx.doi.org/10.1016/j.jtcvs.2017.05.092
}

Improvements in esophagectomy have led to an increase in long-term survivors postesophagectomy. Historically, the literature focused mainly on adequacy of resection and mortality. Postoperative issues including return to work, ingestion of a normal diet, and quality of life (QOL) were not addressed routinely. The general message was, "if you were alive," you were a surgical success. Yet in some, QOL was compromised, and correctable problems existed. ${ }^{1-3}$

Few surgeons have reported on conduit dysfunction in the postesophagectomy population, and the authors should be commended for reporting their experience. ${ }^{2}$ They state that severe gastric conduit dysfunction is rare, yet the lack of long-term QOL data prevent us from determining how many patients struggle postesophagectomy. Unfortunately, there is no simple algorithm for the diagnosis and management of this problem. An esophagram and upper endoscopy are important initial steps, but symptom severity and limitations in QOL should dictate further investigation. Careful analysis of the index esophagectomy may identify risk factors for conduit dysfunction and guide changes for improvement.

The optimal esophagectomy is debatable. There are proponents for many techniques, and one could argue that many may work in experienced hands. However, some centers do not perform long-term follow-up, and, thus, many surgeons do not know their own outcomes.

Many dysfunctional patients postesophagectomy do not need surgery but instead need careful assessment of their diet, lifestyle, medications, etc. Medical management by an experienced team will improve some of these patients without revisional surgery. However, if careful evaluation and nonsurgical management fails, then revisional surgery may be warranted for suboptimal postesophagectomy anatomy.

Revisional surgery for the severely symptomatic patient postesophagectomy requires a tailored approach. Some may simply need management of recalcitrant anastomotic strictures or lysis of adhesions and, thus, the importance of thorough evaluations. Other factors should be considered including disease recurrence, pyloric-emptying problems,

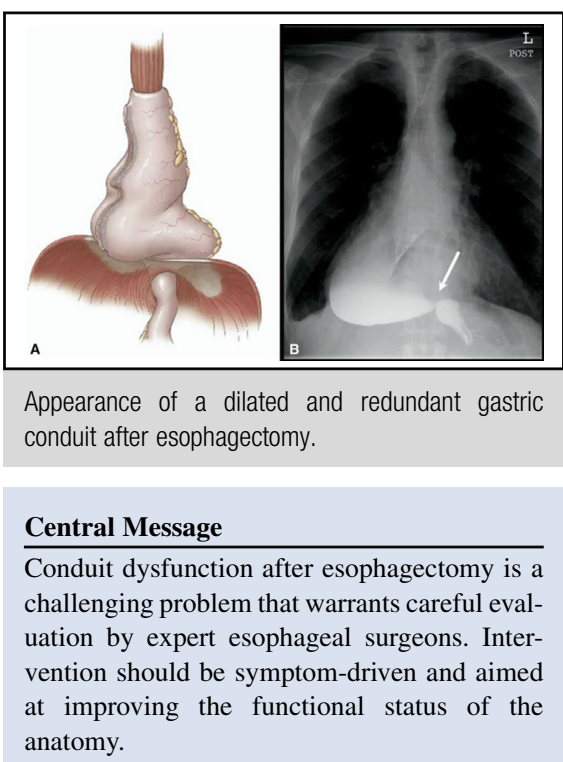

See Article page 1450 .

side effects of high-dose narcotics, etc. However, some patients may harbor a paraconduit colonic hernia, conduit enlargement, angulation, redundancy, or a combination of factors. An enlarged and redundant conduit may mimic end-stage achalasia with a sigmoid loop. A supradiaphragmatic shelf may limit conduit-emptying, requiring complex revision and retubularization.

We recently presented the largest single-institution experience of revisional surgery in 125 patients postesophagectomy who underwent intervention for redundant conduit or paraconduit hernia. ${ }^{3}$ Ninety percent of these severely symptomatic patients had symptom resolution or improvement in QOL. However, these complex operations may require both thoracic and abdominal exploration with significant morbidity; thus, revisional surgery should be considered only for severely symptomatic patients in whom you believe you can improve on their existing anatomy.

Randomized trials and long-term functional data are needed to reach consensus on the ideal esophagectomy that provides the most favorable oncologic and QOL outcomes. Currently, we believe the optimal esophagectomy can be performed minimally invasively and should include complete resection, construction of a straight, narrow conduit avoiding redundancy, a small infradiaphragmatic antral reservoir, and a pyloric-emptying procedure. ${ }^{4}$ Any 
postesophagectomy intervention should be symptomdriven and aimed at improving the functional anatomy.

\section{References}

1. Kent MS, Luketich JD, Tsai W, Churilla P, Federle M, Landreneau R, et al. Revisional surgery after esophagectomy: an analysis of 43 patients. Ann Thorac Surg. 2008;86:975-83; discussion 967-74.
2. Rove JY, Krupnick S, Baciewicz FA, Meyers BF. Gastric conduit revision postesophagectomy-management for a rare complication. Ann Thorac Surg. April 13, 2017 [Epub ahead of print].

3. Schaheen LW, Chan EG, Schaheen B, Levy RL, Awais O, D'Cunha J, et al. Revisional surgery following esophagectomy: straight talk about the conduit. Paper presented at: 53rd STS Annual Meeting; January 21-25, 2017, Houston, Texas.

4. Shah RD, Levy RM, Luketich JD. Minimally invasive Ivor Lewis esophagetomy. In: Luketich JD, ed. Master techniques in surgery: esophageal surgery. Philadelphia, PA: Wolters Kluwer Health; 2014:273-88. 